\title{
Exogenous melatonin alleviates PEG- induced short-term water deficiency in maize by increasing hydraulic conductance
}

\author{
Yujie Qiao ${ }^{1,2}$, Jianhong Ren ${ }^{1,2}$, Lina Yin ${ }^{1,3,4}$, Yijian Liu ${ }^{1,4}$, Xiping Deng ${ }^{1,2,3}$, Peng Liu ${ }^{5}$ and Shiwen Wang ${ }^{1,3,4^{*}}$ (D)
}

\begin{abstract}
Background: Water deficiency is likely to become more frequent and intense as a result of global climate change, which may severely impact agricultural production in the world. The positive effects of melatonin (MEL) on alleviation drought or osmotic stress-induced water deficiency in plants has been well reported. However, the underlying mechanism of MEL on the detailed process of plant water uptake and transport under water deficiency condition remains largely unknown.

Results: Application of $1 \mu \mathrm{M}$ MEL led to enhanced tolerance to water deficiency stress in maize seedlings, as evidenced by maintaining the higher photosynthetic parameters, leaf water status and plant transpiration rate. The relatively higher whole-plant hydraulic conductance $\left(K_{\text {plant }}\right)$ and root hydraulic conductance $\left(L p_{r}\right)$ in MEL-treated seedlings suggest that exogenous MEL alleviated water deficiency stress by promoting root water absorption. $\mathrm{HgCl}_{2}$ (aquaporin inhibitor) treatment inhibit the transpiration rate in MEL-treated plants greater than those of MELuntreated; after recovery by dithiothreitol (DTT, anti-inhibitor), the transpiration rate in MEL-treated plants increased much higher than those of untreated plants. Moreover, under water deficiency, the transcription level of aquaporin genes was up-regulated by MEL application, and the $\mathrm{H}_{2} \mathrm{O}_{2}$ was less accumulated in MEL-treated root.

Conclusions: Exogenous MEL promoted aquaporin activity, which contributed to the maintaining of $L p_{r}$ and $K_{\text {plant }}$ under short-term water deficiency. The increased water uptake and transport lead to improved water status and thus increased tolerance to PEG-induced short-term water deficiency in maize seedlings.
\end{abstract}

Keywords: Aquaporin, Melatonin, Water deficiency, Whole-plant hydraulic conductance, Root hydraulic conductance

\section{Background}

Melatonin (N-acetyl-5-methoxytryptamine, MEL), a ubiquitously distributed natural pleiotropy bio-molecule, has been confirmed to exist from prokaryotes to eukaryotes, animals to plants $[1,2]$. In plants, the positive effects of MEL on regulating plant growth and

\footnotetext{
* Correspondence: shiwenwang@nwsuaf.edu.cn

${ }^{1}$ State Key Laboratory of Soil Erosion and Dryland Farming on the Loess Plateau, Institute of Soil and Water Conservation, Northwest A\&F University, Yangling 712100, Shaanxi, China

${ }^{3}$ Institute of Soil and Water Conservation, Chinese Academy of Sciences \& Ministry of Water Resources, Yangling 712100, Shaanxi, China

Full list of author information is available at the end of the article
}

development have been widely reported, such as promoting seed germination, regulating root and shoot development and adjusting flowering period [1, 3-5]. It has also been widely reported that MEL is involved in regulating plant responses to various biotic and abiotic stresses, such as improve the resistance of plants to drought, cold, heat, osmotic stress, herbicides, UV irradiation and oxidative stress [5]. Meanwhile, various physiological processes have also been found to be involved in MEL regulating plant stress resistance, including increased antioxidant capacity; delayed leaf senescence, promoted development of root system, maintained chlorophyll content and photosynthetic

C The Author(s). 2020 Open Access This article is licensed under a Creative Commons Attribution 4.0 International License, which permits use, sharing, adaptation, distribution and reproduction in any medium or format, as long as you give appropriate credit to the original author(s) and the source, provide a link to the Creative Commons licence, and indicate if changes were made. The images or other third party material in this article are included in the article's Creative Commons licence, unless indicated otherwise in a credit line to the material. If material is not included in the article's Creative Commons licence and your intended use is not permitted by statutory regulation or exceeds the permitted use, you will need to obtain permission directly from the copyright holder. To view a copy of this licence, visit http://creativecommons.org/licenses/by/4.0/ The Creative Commons Public Domain Dedication waiver (http://creativecommons.org/publicdomain/zero/1.0/) applies to the data made available in this article, unless otherwise stated in a credit line to the data. 
electron transport systems, promoted photosynthetic rate, and so on [6-8]. Recent transcriptome studies have also demonstrated that plant hormones, such as abscisic acid, auxin and gibberellin are also involved in the signaling pathways of MEL regulating plant stress responses [9].

Drought or osmotic stress-induced water deficiency is one of the most severe abiotic stresses in agricultural production, and MEL has been widely reported to improve plant tolerance to water deficiency stress in various plants [7, 10-13]. Numbers of physiological and biochemical processes have been reported to be involved in MEL-mediated plant water deficiency stress response. Among them, MEL-mediated scavenging of reactive oxygen species by increasing antioxidant capacity has been proved to be an important mechanism for improving plant tolerance to water deficiency stress $[12,14]$. It has been reported that exogenous MEL was able to increase not only the activities of many antioxidant enzymes, including catalase, superoxide dismutase, peroxidase and ascorbate peroxidase, but also the level of nonenzymatic antioxidants, including glutathione and ascorbate, as well as the expression level of related genes to increase the antioxidant capacity of drought-stressed plants $[15,16]$. In addition, exogenous MEL can also promote the biosynthesis of endogenous melatonin under drought stress, which has been shown to directly donate electrons to scavenge free radicals [17, 18]. MEL can also delay drought-induced leaf senescence by scavenging reactive oxygen species [19]. Rhizosphere application of MEL $(10 \mu \mathrm{M})$ was found to promote the nitrogen metabolism and proline homeostasis in drought-stressed alfalfa, and finally lead to a higher level of chlorophyll fluorescence and stomatal conductance [6].

The drought and osmotic stress-induced damage in plants is mainly due to the water shortage or the imbalance of plant water absorption and loss. Therefore, maintaining plant water balance by reducing water loss or increasing root water absorption is an essential way for improving the plant tolerance to water deficiency stress [20]. MEL application has been widely shown to improve plant drought and osmotic stress tolerance, but its effect on plant water balance has been largely ignored. Although previous research has reported that MEL could maintain the leaf relative water contents by increasing the osmotic adjustment ability [6], less research has been focused on the function of MEL on plant water balance, especially on the plant water uptake and transport ability.

The overall water uptake and transport ability in plant is represented by the whole-plant hydraulic conductance $\left(\mathrm{K}_{\text {plant }}\right)$, which consists of leaf, stem and root hydraulic conductance $\left(\mathrm{Lp}_{\mathrm{r}}\right)$ [21]. In plant water transport system, $\mathrm{Lp}_{\mathrm{r}}$ is the limited factor of overall plant water uptake under water deficiency condition [22]. $\mathrm{Lp}_{\mathrm{r}}$ is mainly regulated by aquaporin activity before the change of root morphology and structure, it plays a prominent role in plant response to short-term water deficiency stress [23]. It has been shown that MEL could significantly increase the mRNA expression level of aquaporin and the protein level of aquaporin isoforms in animals [24]. In addition, during the postharvest life in tomato, MEL treatment increased the expression of aquaporin genes with enhanced water loss in tomato fruit [25]. These studies suggest that MEL may also be able to increase water absorption capacity by regulating aquaporins in plant roots.

Therefore, the aim of the present study was to test the hypothesis that MEL improves the plant drought resistance by regulating the $K_{\text {plant }}$. Maize seedlings were grown in hydroponic solution with and without MEL $(1 \mu \mathrm{M})$, and $10 \%$ polyethylene glycol (PEG) 6000 was used for inducing water deficiency. The photosynthesis, leaf water status and plant transpiration were determined. $\mathrm{K}_{\text {plant }}$, root xylem osmotic potential, $\mathrm{Lp}_{\mathrm{r}}$ and the expression level of aquaporin genes were also investigated to exploring the regulation of plant hydraulic conductance by exogenous MEL under water deficiency condition.

\section{Results}

Effects of MEL application on the photosynthetic capacity under water deficiency stress

Under control condition, MEL application did not affect photosynthetic parameters in maize seedlings significantly. However, after exposed to water deficiency stress, all the photosynthetic parameters, including photosynthetic rate, stomatal conductance and transpiration rate, were reduced rapidly, but they were significant higher in MEL-treated seedlings than that without MEL-treated. Under water deficiency condition, the photosynthetic rate, stomatal conductance and transpiration rate were 46.6, 39.5 and 46.8\% higher in MEL-treated seedlings than those without MEL treatment, respectively (Fig. 1).

\section{Application of MEL contribute to maintaining water status under water deficiency stress}

The whole plant transpiration rate was observed from the onset of PEG treatment to investigate the effect of exogenous MEL on the alteration of whole-plant water status under water deficiency condition. The transpiration rate fluctuated slightly at the beginning of the treatment and the significant difference began to occur after three hours of PEG treatment (11:00 a.m.), at which time point the whole-plant transpiration rate was higher in MEL-treated seedlings than that untreated, and this tendency was continued during the subsequent observation period (Fig. 2). 


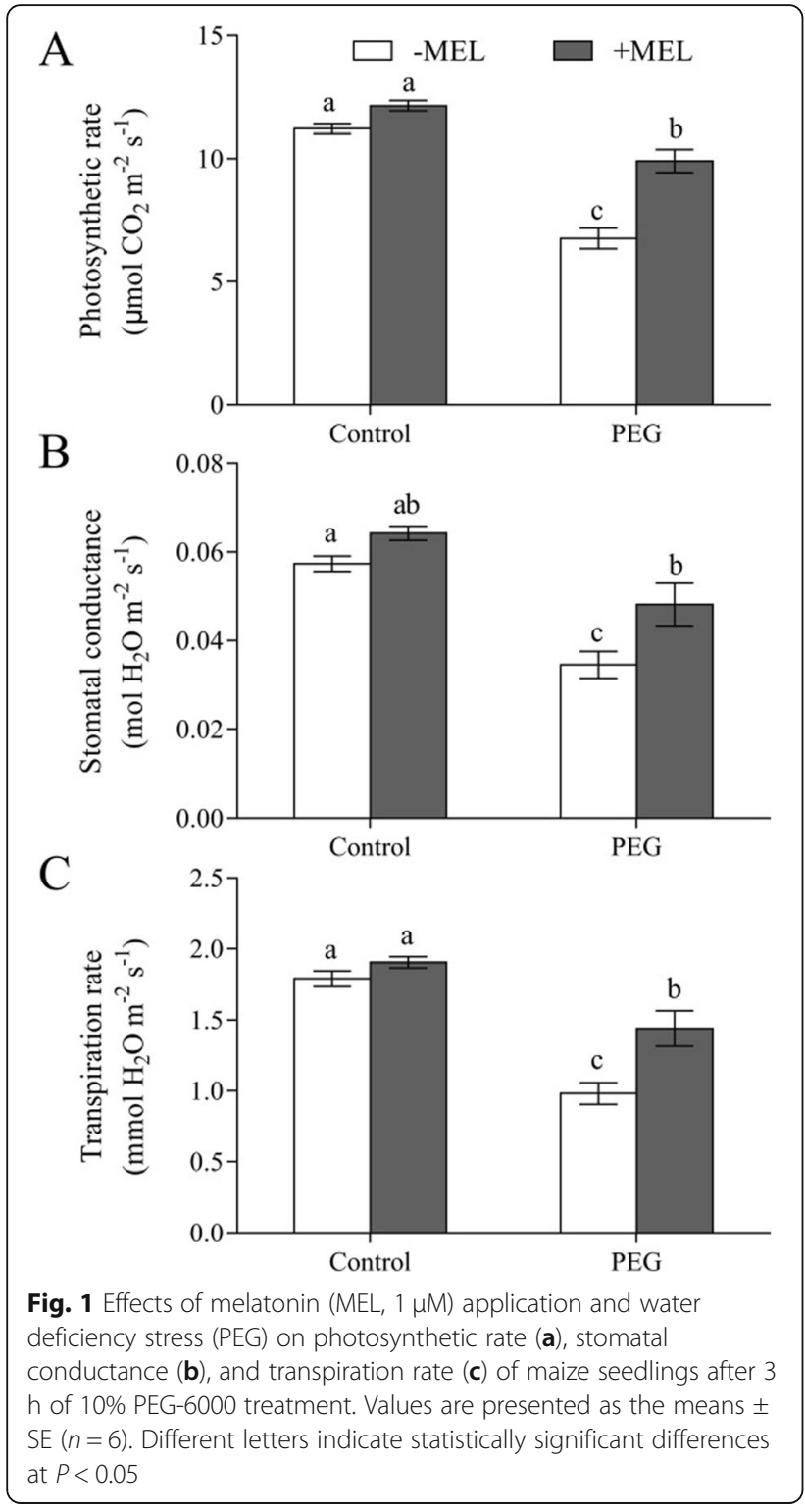

In the present study, the leaf relative water content (LRWC) did not change under control condition neither with nor without MEL application. However, it was decreased after three hours of water deficiency stress, while the MEL application significantly alleviated the stressinduced decrease in LRWC (Fig. 3a). After exposed to water deficiency stress for three hours, the leaf water potential in MEL-treated plants $(-0.37 \mathrm{MPa})$ also showed significantly higher than those of untreated $(-0.44 \mathrm{M} \mathrm{Pa})$ (Fig. 3b). Furthermore, water deficiency stress significantly enhanced the leaf osmotic potential, but exogenous MEL reduced the water deficiency-induced increase in leaf osmotic potential, which showed $12.5 \%$ higher in MEL-treated seedlings than that without MEL treatment (Fig. 3c).
Exogenous MEL improved the water status by maintaining a high $\mathrm{K}_{\text {plant }}$ and $L p_{\mathrm{r}}$

Exogenous MEL had no obviously effect on the $K_{\text {plant }}$ under control condition (Fig. 4). After exposure to PEG treatment, the $\mathrm{K}_{\text {plant }}$ was significantly decreased, but it was still higher in MEL-treated plants than that in MELuntreated plants. The $\mathrm{K}_{\text {plant }}$ was $4.55 \mathrm{mmol} \mathrm{H}_{2} \mathrm{O} \mathrm{m} \mathrm{m}^{-2}$ $\mathrm{s}^{-1} \mathrm{MPa}^{-1}$ in MEL-treated plants, which was $58 \%$ higher than that of untreated plants $\left(2.88 \mathrm{mmol} \mathrm{H}_{2} \mathrm{O} \mathrm{m}^{-2} \mathrm{~s}^{-1}\right.$ $\mathrm{MPa}^{-1}$ ). Similarly, the $\mathrm{Lp}$ r also showed no significant difference regardless of MEL treatment under control condition (Fig. 5a, b). However, after exposed to PEG stress, the $\mathrm{Lp}_{\mathrm{r}}$ of MEL-treated plants was $6.67 \times 10^{-8}$ $\mathrm{m}^{3} \mathrm{~m}^{-2} \mathrm{~s}^{-1} \mathrm{MPa}^{-1}$, whereas it was only $4.37 \times 10^{-8} \mathrm{~m}^{3}$ $\mathrm{m}^{-2} \mathrm{~s}^{-1} \mathrm{MPa}^{-1}$ in MEL-untreated plants, which was 34.5\% lower than that in MEL-treated plants. Furthermore, the short-term MEL treatment did not affect root surface area of maize seedlings, indicating that the enhanced root water uptake in MEL-treated plants could not be ascribed to the promoting of root growth (Fig. 5c).

\section{MEL application improved the whole-plant transpiration by increasing aquaporin activity}

The osmotic potential of root xylem sap in the present study was not affect by MEL application under both control and PEG-stressed condition (Fig. 6). In the presence of $\mathrm{HgCl}_{2}$, the transpiration rate in MEL-treated and untreated plants decreased to the same level. After a recovery induced by DTT, the transpiration rate in MELtreated plants were $37 \%$ higher than that of untreated (Fig. 7).

In addition, the expression levels of plasma membrane intrinsic aquaporins (PIPs) were up-regulated by MEL application under control condition. After $3 \mathrm{~h}$ of PEG treatment, the expressions of ZmPIP1;2 and ZmPIP2;5 were up-regulated by exogenous MEL. While after $6 \mathrm{~h}$ of PEG treatment, the expressions of ZmPIP1;2, ZmPIP1;5, $Z m P I P 2 ; 2$ and $Z m P I P 2 ; 5$ were all up-regulated by exogenous MEL (Fig. 8).

\section{Effects of MEL application on $\mathrm{H}_{2} \mathrm{O}_{2}$ content under water deficiency stress}

The $\mathrm{H}_{2} \mathrm{O}_{2}$ contents were lower in MEL-treated seedlings than that without MEL treatment under both control and water deficiency conditions. Moreover, the root $\mathrm{H}_{2} \mathrm{O}_{2}$ content increased sharply when exposed to PEG treatment, but it was kept at the same level as that in control plants (without MEL application) by MEL application (Fig. 9).

\section{Discussion}

Water deficiency caused stomatal closure or destruction in photosynthetic reaction centers easily in plants, which 


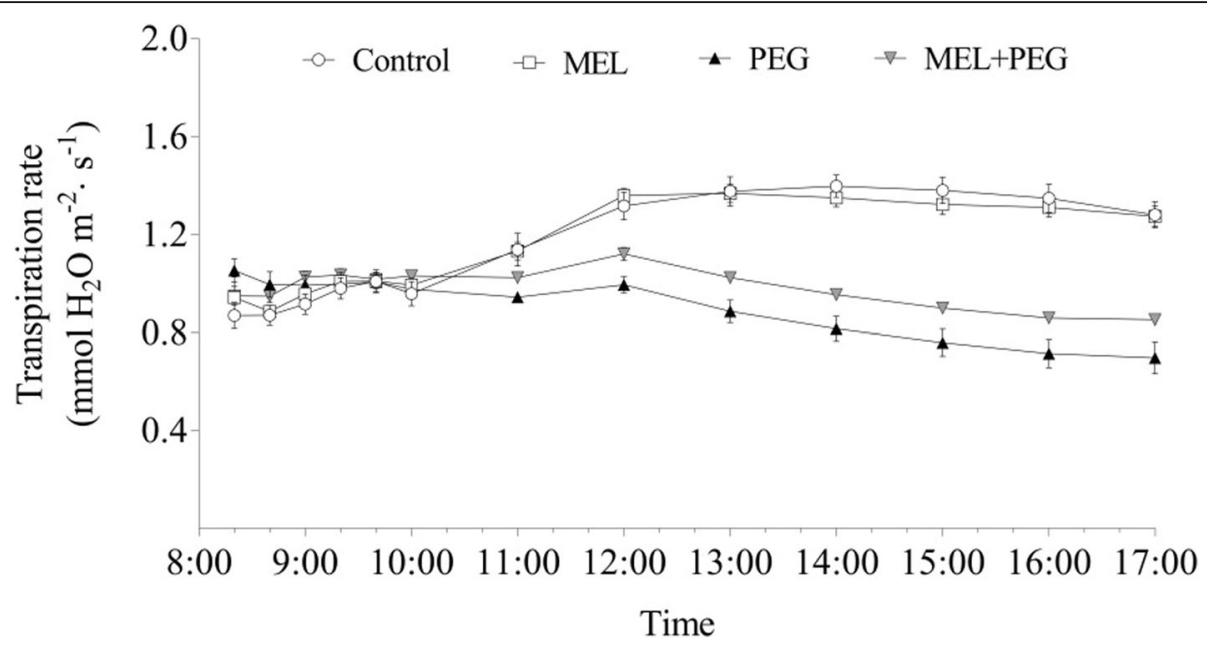

Fig. 2 Effects of melatonin (MEL, $1 \mu M$ ) application and water deficiency stress (PEG) on transpiration rate of maize seedlings in hydroponic culture. The transpiration rate was determined gravimetrically from the initial of PEG treatment at 08:00 a.m. (turn on the light). Values are presented as the means $\pm \mathrm{SE}(n=8)$. Different letters indicate statistically significant differences at $P<0.05$

can lead to the seriously decline of photosynthetic rate and ultimately affect the accumulation of dry matter [26, 27]. In the current study, our results showed that the water deficiency-induced reduction of photosynthetic rate was moderated in MEL-treated seedlings (Fig. 1), indicating that MEL application could alleviate plant water deficiency stress in maize seedling. Due to the short duration of MEL and PEG treatment, there was no visible differences in the dry weight between with and without MEL treatment (Fig. S1). In short term water deficiency stress, the main reason for the decrease of photosynthesis is caused by stomatal closure because of insufficient water supplied $[28,29]$. In this study, compared with MEL-untreated plants, MEL-treated plants maintained high stomatal conductance, LRWC and transpiration rate under PEG treatment, suggesting that MEL could contribute to maintaining the water status of maize seedlings under water deficiency condition, which in turn favored in maintaining high transpiration and photosynthesis, and lead to improved plant water stress tolerance (Figs. 1, 2, 3). In addition, the influence of MEL on transpiration showed dose effect (Fig. S2).

The maintenance of plant water status depends on the coordinated balance among water absorption, transport and transpiration [30]. Ding et al. [31] have reported that exogenous application of MEL improved tomato tolerance to water deficiency by promoting cuticle formation to restrict water loss. In this study, due to the short duration of MEL and PEG treatment (only $24 \mathrm{~h}$ and $6 \mathrm{~h}$, respectively), it is impossible for plant to reduce the loss of water by adjusting cuticle formation. Meanwhile, in this study, melatonin-treated plants maintained a relatively large stomatal conductance (Fig. 1b) and a higher whole plant transpiration rate (Fig. 2) under water deficiency stress. Such a large loss of water dispersion could not be ascribed to the water maintenance of the leaves under water deficiency stress, suggesting that MEL may alleviate the short-term water deficiency by increasing water absorption and transportation.

The $\mathrm{K}_{\text {plant }}$ represents the soil-to-leaf water transport capacity [21]. In this study, the $K_{\text {plant }}$ was $58 \%$ higher in MEL-treated seedlings than that of untreated under water deficiency condition (Fig. 4), indicating that MEL could contribute to high water uptake capability under this condition. The $K_{\text {plant }}$ consists of leaf $\left(K_{\text {leaf }}\right)$, stem $\left(\mathrm{K}_{\text {stem }}\right)$ and root hydraulic conductance $\left(\mathrm{Lp}_{\mathrm{r}}\right)$ [21]. In previous studies, it has been clearly proved that the seedlings used in this experiment could not form stem due to the young age and short-term treatment [32], therefore, the $K_{\text {plant }}$ can only be affected by $K_{\text {leaf }}$ and $\mathrm{Lp}_{\mathrm{r}}$. In this study, $\mathrm{K}_{\text {leaf }}$ was not measured because of the technical limitations. Brodribb et al. [33] showed that $K_{\text {leaf }}$ is very similar to the leaf water potential, so we used leaf water potential to characterize the effect of MEL treatment on $K_{\text {leaf }}$. Under water deficiency condition, MEL treatment significantly improved the water potential by $15.9 \%$ (Fig. 3). The $\mathrm{Lp}_{\mathrm{r}}$ represents the root water uptake capacity, and its regulation plays an important role in maintaining the water status of the entire plant [34]. Under water deficiency condition, the $\mathrm{Lp}_{\mathrm{r}}$ extremely limited the water uptake and transport [22]. In this study, after exposed to water deficiency stress, the $\mathrm{Lp}_{\mathrm{r}}$ in MEL-treated plants was $52.5 \%$ higher than that of MEL-untreated plants. Meanwhile, under water deficiency condition, the increase of $K_{\text {plant }}$ and $\mathrm{Lp}_{\mathrm{r}}$ in MELtreated plants exhibited the similar extent, which were 58 and $52.5 \%$ higher respectively (Figs. 4 and 5), suggesting that MEL could alleviate the water stress by 


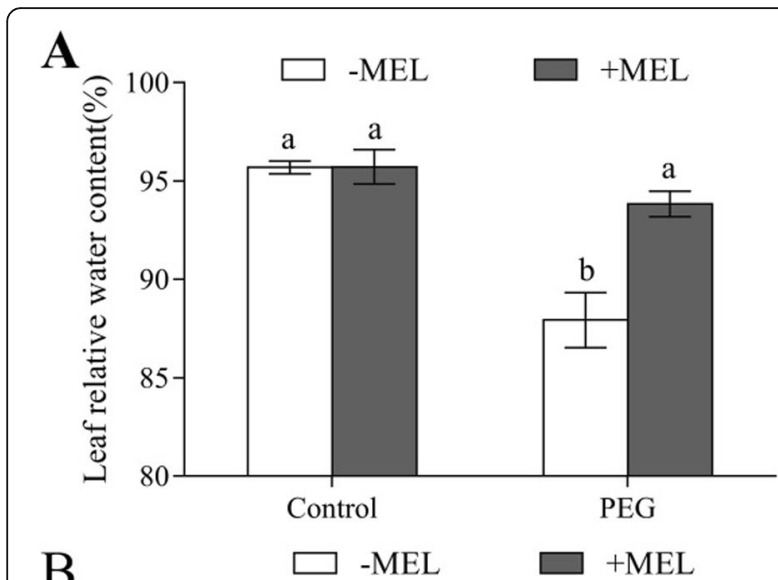

B
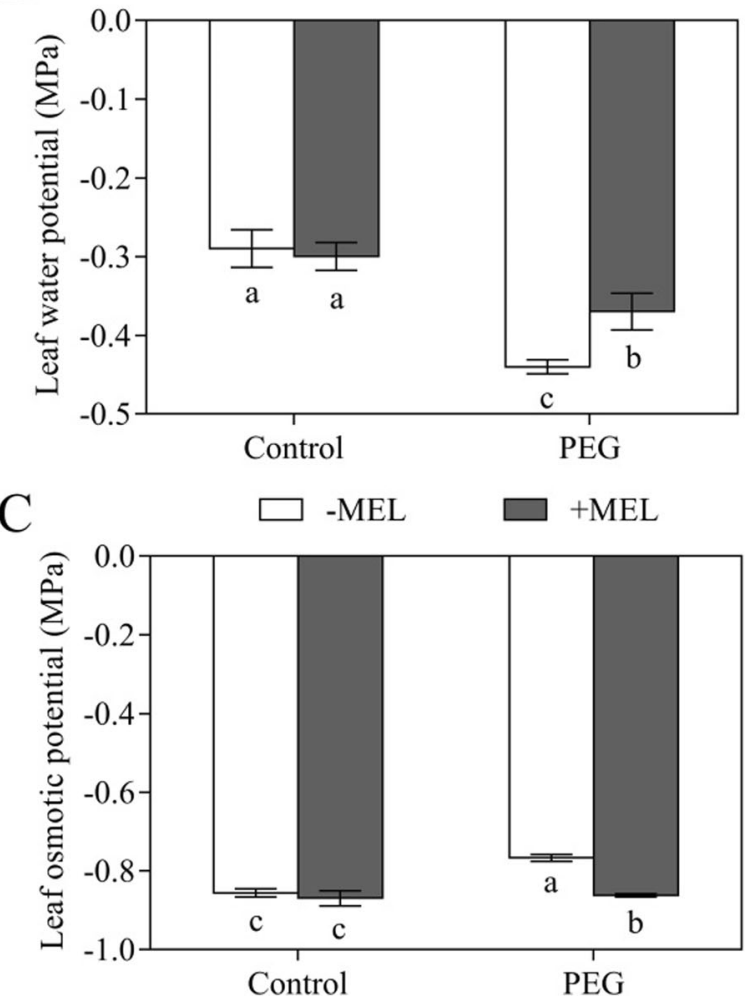

Fig. 3 Effects of melatonin (MEL, $1 \mu \mathrm{M}$ ) application and water deficiency stress (PEG) on leaf relative water content (LRWC) (a), leaf water potential (b) and leaf osmotic potential (c) of maize seedlings in hydroponic culture. All parameters were determined after $3 \mathrm{~h}$ of PEG-6000 treatment. Values are presented as the means \pm SE $(n=6)$. Different letters indicate statistically significant differences at $P<0.05$

regulating water uptake through improving the $\mathrm{Lp}_{\mathrm{r}}$. The changing extent of $K_{\text {plant }}$ is slightly higher than $L_{p}$, suggesting that the high $K_{\text {leaf }}$ in MEL-treated plants also contribute to the improvement of $\mathrm{K}_{\text {plant }}$ and the influence of the MEL on the $K_{\text {leaf }}$ should also be investigated in the further study.

In root, radial water transport across cell membranes includes three pathways: apoplastic, symplastic and transcellular, and the latter two pathways together were called the "cell-to-cell" pathway [35]. Under normal growth condition (no water stress), plants absorb and transport water mainly through the apoplastic pathway, which is not regulated by aquaporins. In this study, under control condition, the MEL-treatment-induced up-regulation of aquaporin genes' expression did not cause changes in root water absorption (Fig. 5). In addition, under normal condition, MEL treatment did not significantly affect the transpiration rate of maize seedlings (Fig. 2). Therefore, MEL treatment did not affect the water balance under normal water condition. Under abiotic stress, "cell-to-cell" pathway is the main water transport way, which is largely regulated by aquaporin [34, 36, 37]. Except for aquaporin, driving force of water transport, the root structure and its area could also influence the $\mathrm{Lp}_{\mathrm{r}}[32,38]$. In our study, due to the short duration of MEL and PEG treatments, no visible change in root area and structure could be observed. Meanwhile, MEL treatment did not cause the change in xylem osmotic potential (Fig. 6). Taken together, aquaporin could be the main contributor for maintaining high Lpr in MEL-treated plant under water deficiency condition.

In the present study, aquaporin inhibitor and antiinhibitor were used to investigate whether aquaporins are involved in regulation of plant hydraulic conductance has been widely reported previously [32, 39]. Here, $\mathrm{HgCl}_{2}$, a specific aquaporin activity inhibitor was used to eliminate the transpiration difference between MELtreated and MEL-untreated plants. Under PEG treatment, the transpiration rates of seedlings were significantly higher in MEL treated plants than without MELtreated plants. However, the transpiration rates in both MEL-treated and untreated plants were decreased to the same level after $5 \mathrm{~min} \mathrm{HgCl}_{2}$ treatment. After recovery induced by DTT, the transpiration rates in MEL-treated seedlings were $37 \%$ higher than that measured in seedlings without MEL (Fig. 7). According to the homology and structural characteristics of amino acid sequences, plant aquaporins can be divided into Plasma membrane intrinsic aquaporins (PIPs), tonoplast intrinsic aquaporins (TIPs), nodulin 26-like aquaporins (NIPs), small basic intrinsic aquaporins (SIPs) [40]. TIPs are located on the vacuole membrane and mainly regulate the water transport between cytoplasm and vacuole. NIPs are located on the symbiotic membrane of rhizobia and legumes. SIPs are located on the endoplasmic reticulum membrane. Among these four types of aquaporins, PIP have shown to play the important role on the regulation of plant water homeostasis under water deficiency condition [21, 41]. Numerous studies have shown that the trafficking dynamics of PIPs is essential to improve root water absorption and leaf physiological conditions under drought stress [42, 43]. In this study, the transcript levels 


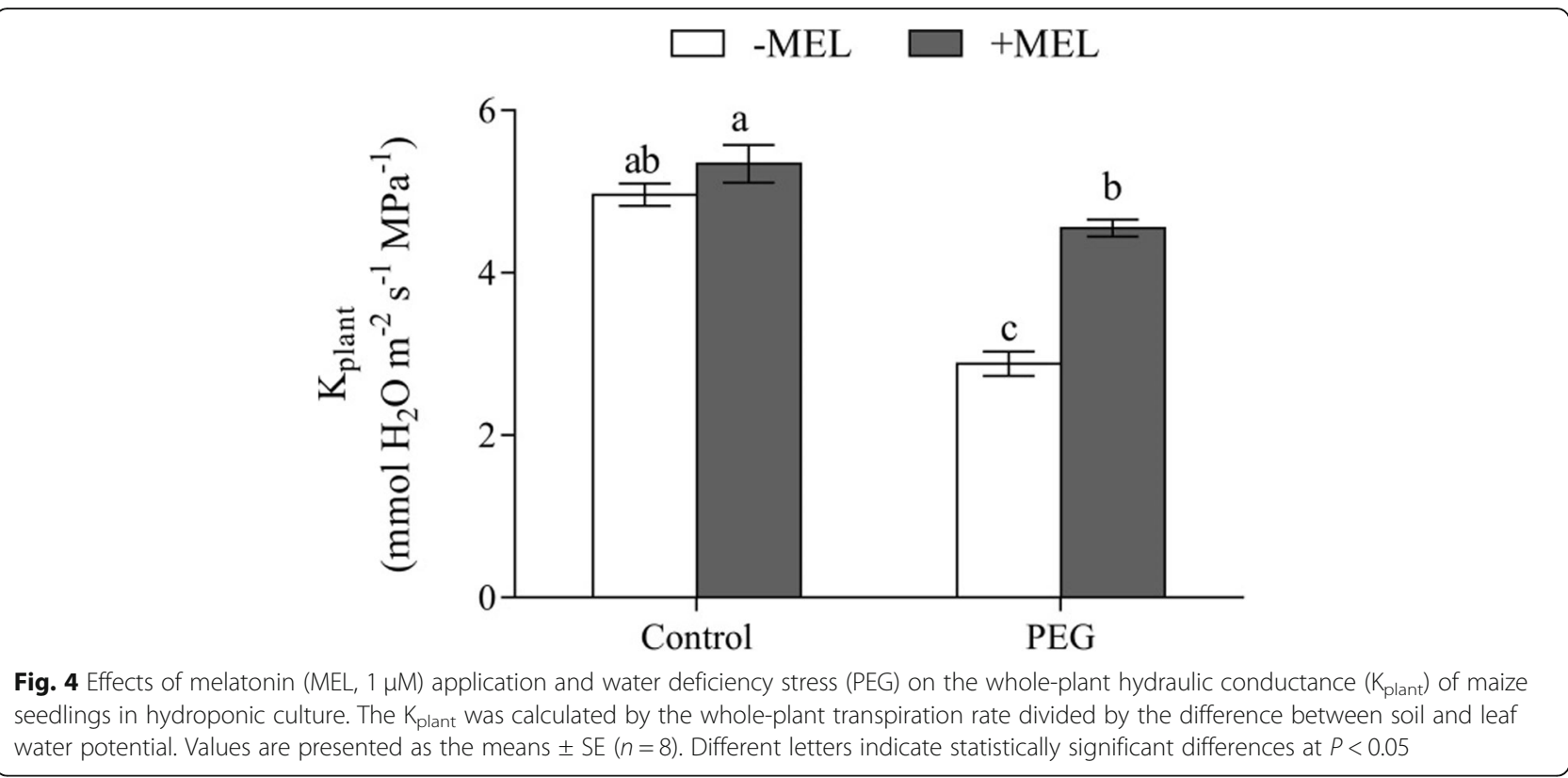

of aquaporin genes, including ZmPIP1;2, ZmPIP1;5, $Z m P I P 2 ; 2$ and ZmPIP2;5, were significantly higher in MEL-treated plants than in untreated ones under both control and PEG treatment (Fig. 8). These results indicate that aquaporin activity was enhanced by MEL application which could contribute to the alleviation of water deficiency-induced decrease in $\mathrm{Lp}$. In this study, only the PIP transcript levels in the root were investigated, the whole aquaporins genes should be investigated both in root and leaf in the further study if the complex function of the aquaporins on the whole plant water balance is considered.

In this study, we found that MEL application enhanced the $L p_{r}$ by regulating the aquaporin activity, but the further molecular mechanism of this performance is not clear. Aquaporin activity is also affected by a number of plant hormones and regulators, such as salicylic acid, ethylene, $\mathrm{Ca}^{2+}$, and reactive oxygen species [44-46]. Although the molecular mechanisms of the MEL on the plant development and action were poorly understood, there are at least three approaches could be concluded based on the previous and current studies in animal and plants. Previous studies have largely shown that the accumulation of hydrogen peroxide can lead to the decrease of aquaporin activity [44, 47-50]. In the present study, the $\mathrm{H}_{2} \mathrm{O}_{2}$ levels in MEL-treated plants were significantly lower than that of untreated ones (Fig. 9), suggesting that MEL may be beneficial in maintaining aquaporin activity through reducing the accumulation of $\mathrm{H}_{2} \mathrm{O}_{2}$. On the other hand, the role of MEL in improving the antioxidant activity has also been considered as the main function for MEL to improve plant stress tolerance $[1,10,18]$. Therefore, MEL may regulate aquaporin activity through scavenging of hydrogen peroxide. Studies in animals have shown that exposure to MEL can induce an increase in intracellular cyclic adenosine monophosphate levels [51]. Upon cyclic adenosine monophosphate elevation, it will cause a decrease of phosphorylation and poly-ubiquitination and hence facilitates the trafficking aquaporin bearing vesicles to the plasma membrane [52]. In addition, more evidence showed that there is significant crosstalk between MEL and other plant hormones, including: cytokinin, salicylic acid, jasmonic acid, gibberellins, abscisic acid and ethylene $[2,50-55]$. Although no direct evidence has been shown up to date that MEL could regulate aquaporin activity by affecting plant hormones or signaling molecules, considering the extensive interaction between MEL and plant hormones, the possibility that MEL regulates aquaporin activity through plant hormones or signaling molecules cannot be ignored.

\section{Conclusions}

Numerous studies have shown that MEL plays an important role in plants to improve various environmental stress tolerance. This study showed that exogenous MEL improves plant water deficiency tolerance by regulating water absorption. Based on previous and our current study, the potential mechanism diagram of MEL on alleviating short-term water deficiency stress was proposed. (1) Under PEG treatment, MEL application enhanced aquaporin activity with decreased $\mathrm{H}_{2} \mathrm{O}_{2}$ accumulation and upregulated the transcription of ZmPIP genes. (2) The performance of PEG-induced decrease in $\mathrm{Lp}_{\mathrm{r}}$ and $K_{\text {plant }}$ were mitigated by the high aquaporin activity. (3) The high $\mathrm{K}_{\text {plant }}$ was beneficial to maintaining the high 

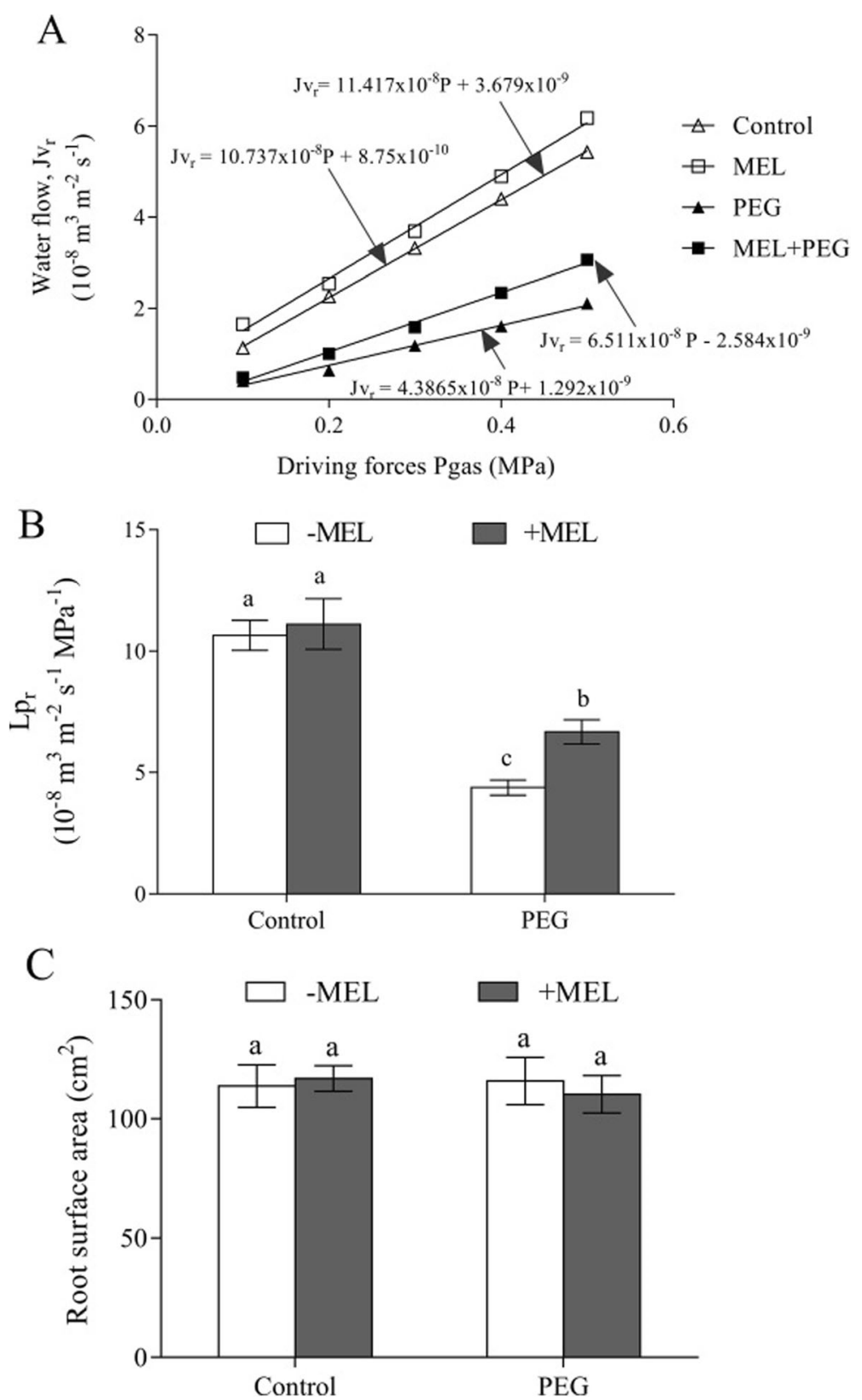

Fig. 5 Effects of melatonin (MEL, $1 \mu \mathrm{M})$ application and water deficiency stress (PEG) on the water flow $\left(J v_{\mathrm{r}}\right)(\mathbf{a})$, root hydraulic conductance $\left(L p_{r}\right)$ $(\mathbf{b})$, and root surface area (c) of maize seedlings in hydroponic culture. Values are presented as the means \pm SE $(n=6)$. Different letters indicate statistically significant differences at $P<0.05$

leaf water content, stomatal conductance, and photosynthetic rate, thereby, enhancing the tolerance to water deficiency stress (Fig. 10). In addition, the underlying mechanisms by which MEL promotes the up-regulation of aquaporin gene expression remain unclear, and future work should be carried out from the aspects of intrinsic molecular mechanisms or signaling pathways of MEL on regulation of plant hydraulic conductance. Moreover, under water-deficient condition, plants could also maintain water balance by increasing root water uptake and/ or reducing leaf water loss. Since our current study is a short-term water stress, how MEL regulates plant water balance from the aspects of water uptake and loss under long-term water stress condition still needs more research.

\section{Methods}

Plant materials, growth condition and MEL treatment The commercial hybrid maize seeds [Zea mays (L.), cv. Zhengdan958] were bought from Shandong Ruiyou 


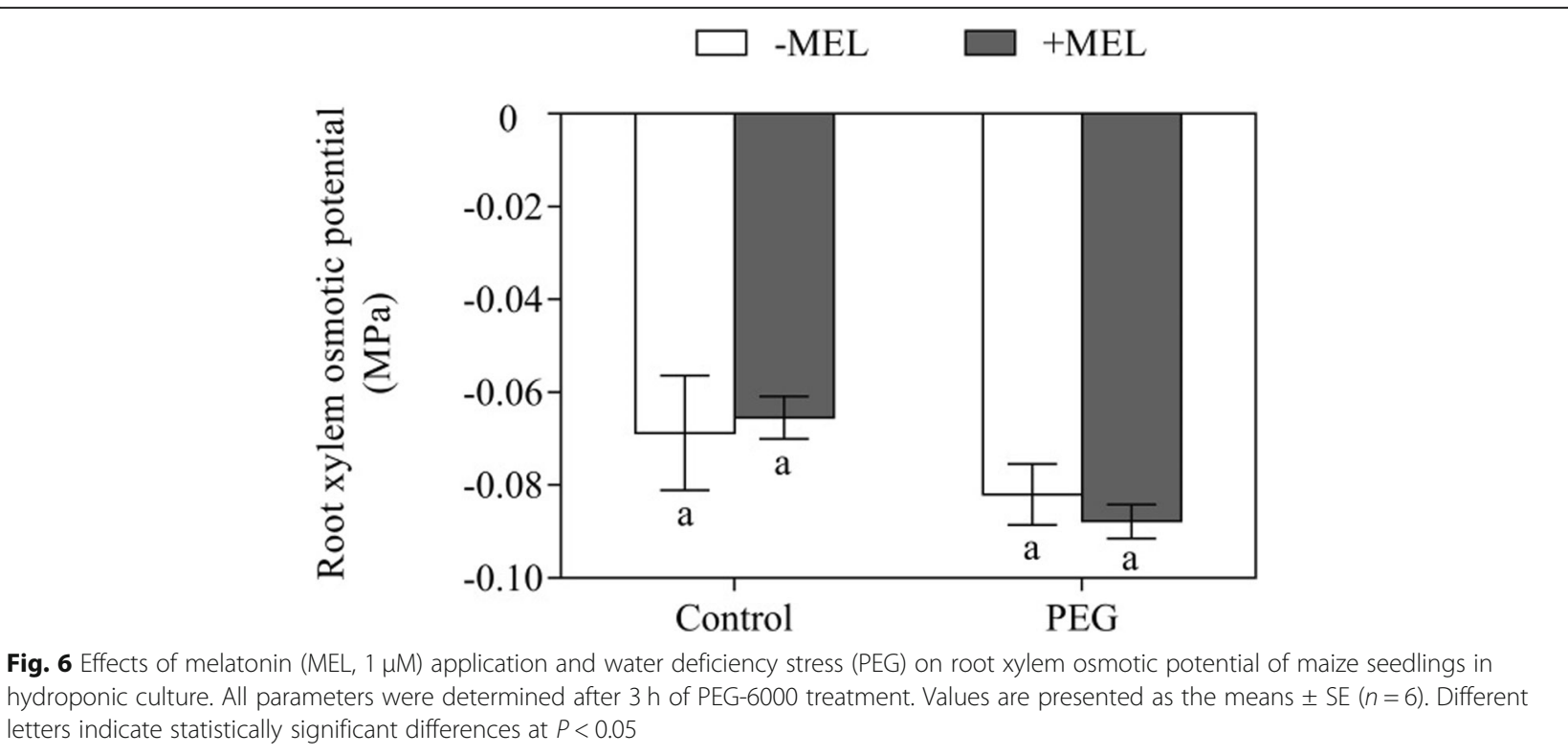

Agriculture and Technology Development Company Limited (Jinan City, Shandong Province, China), and this cultivar is a widely grown cultivar in China. The experiment was carried out in a growth chamber which was set to a $14 / 10 \mathrm{hday} /$ night cycle at the temperature of $28 / 25^{\circ} \mathrm{C}$ with 40 to $50 \%$ relative humidity. The amount of photosynthetically active radiation at the upper plant was $500 \mu \mathrm{mol} \mathrm{m}{ }^{-2} \mathrm{~s}^{-1}$. Seeds of maize were germinated on two layers of moist filter paper for 3 days in an incubator under dark conditions at $28^{\circ} \mathrm{C}$. After germination, uniform seedlings $(6 \pm 0.5 \mathrm{~cm}$ high $)$ were selected and transplanted into a plastic container $(40 \times 28 \times 14 \mathrm{~cm})$ with 51 of half strength Hoagland culture solution for growing. After six days of transplanting, the plants were divided into two parts for $0 \mu \mathrm{M}$ or $1 \mu \mathrm{M}$ MEL treatment, respectively. The culture solution was continuously aerated, and the $\mathrm{pH}$ was adjusted to 6.0 with $0.1 \mathrm{M} \mathrm{HCl}$ or 1 $\mathrm{M} \mathrm{KOH}$ every day. Twenty-four hours after MEL treatment, 10\% PEG-6000 was added at 8:00 a.m. for simulating water deficiency stress. The PEG treatment was added and lasted for $10 \mathrm{~h}$. Thus, four treatments: Control, MEL, PEG and MEL+PEG were included in this experiment.

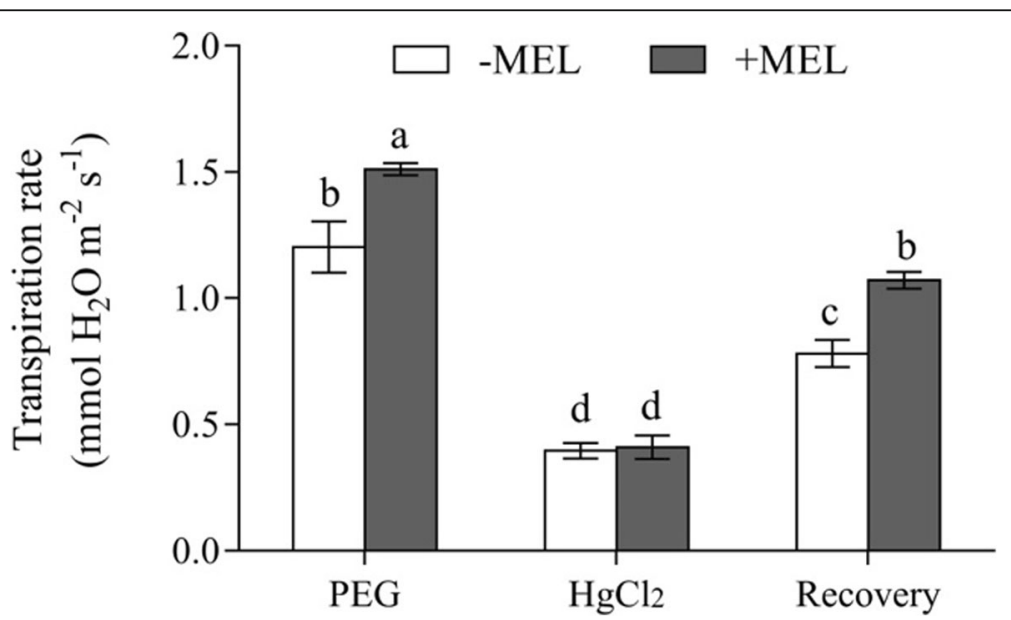

Fig. 7 Effects of $\mathrm{HgCl}_{2}$ (aquaporin inhibitor) and DTT (dithiothreitol, anti-inhibitor) on the transpiration rate of MEL treated and untreated maize seedlings under water deficiency stress (PEG). After $3 \mathrm{~h}$ of PEG treatment, the seedlings were divided as follows: one group determined the transpiration rate directly, another group was treated with $50 \mu \mathrm{M} \mathrm{HgCl}_{2}$ for $5 \mathrm{~min}$ and then rinsed with distilled water before determining the transpiration rate, and the other was exposed to $50 \mathrm{\mu M} \mathrm{HgCl}_{2}$ (5 min) and $5 \mathrm{mM} \mathrm{DTT} \mathrm{(15} \mathrm{min)} \mathrm{before} \mathrm{measuring} \mathrm{the} \mathrm{transpiration} \mathrm{rate.} \mathrm{Values} \mathrm{are}$ presented as the means $\pm \mathrm{SE}(n=8)$. Different letters indicate statistically significant differences at $P<0.05$ 

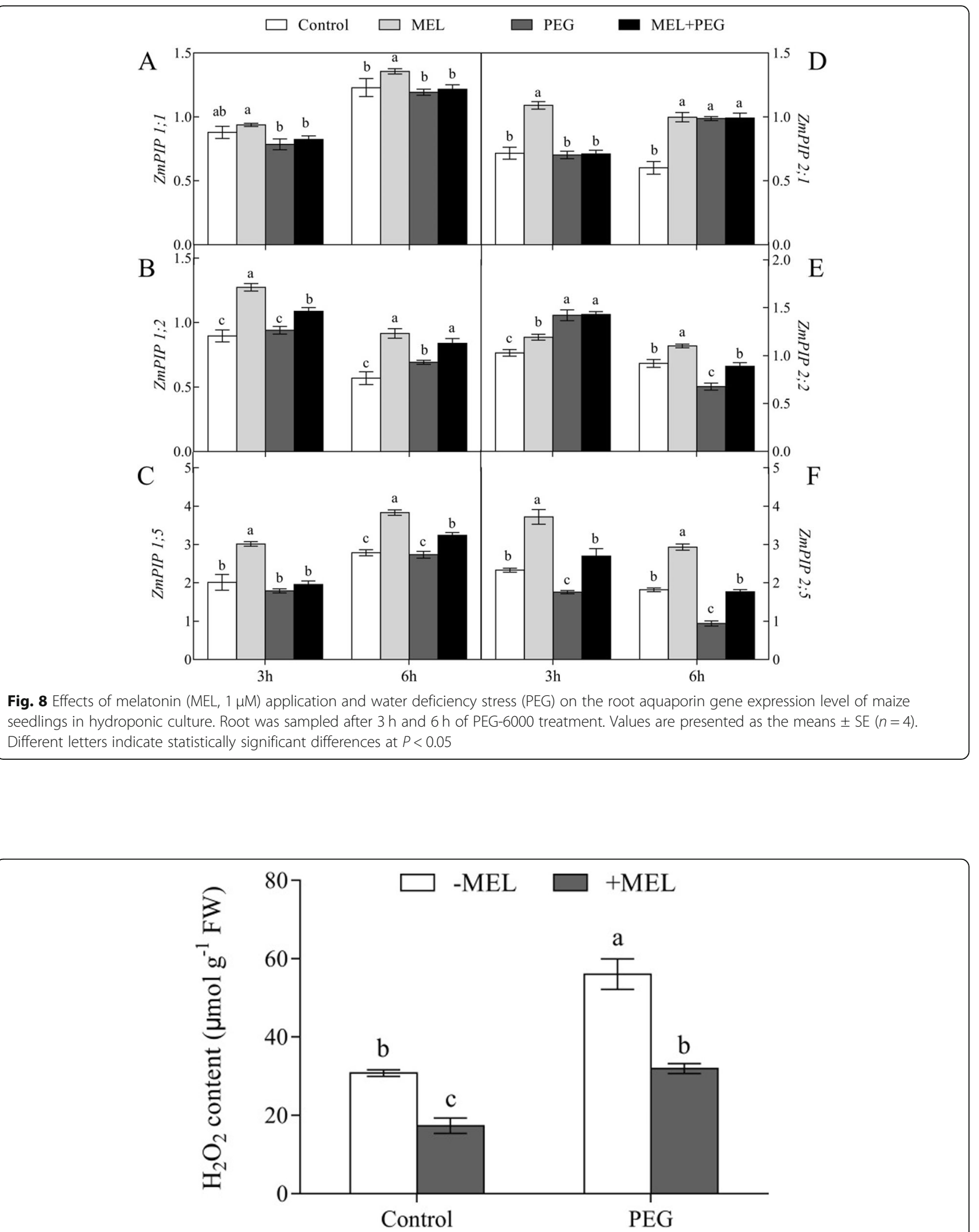

Fig. 9 Effects of melatonin (MEL, $1 \mu \mathrm{M}$ ) application and water deficiency stress (PEG) on root $\mathrm{H}_{2} \mathrm{O}_{2}$ content of maize seedlings in hydroponic culture. $\mathrm{H}_{2} \mathrm{O}_{2}$ content was measured after $3 \mathrm{~h}$ of $10 \%$ PEG-6000 treatment. Values are presented as the means $\pm \mathrm{SE}(n=6)$. Different letters indicate statistically significant differences at $P<0.05$ 


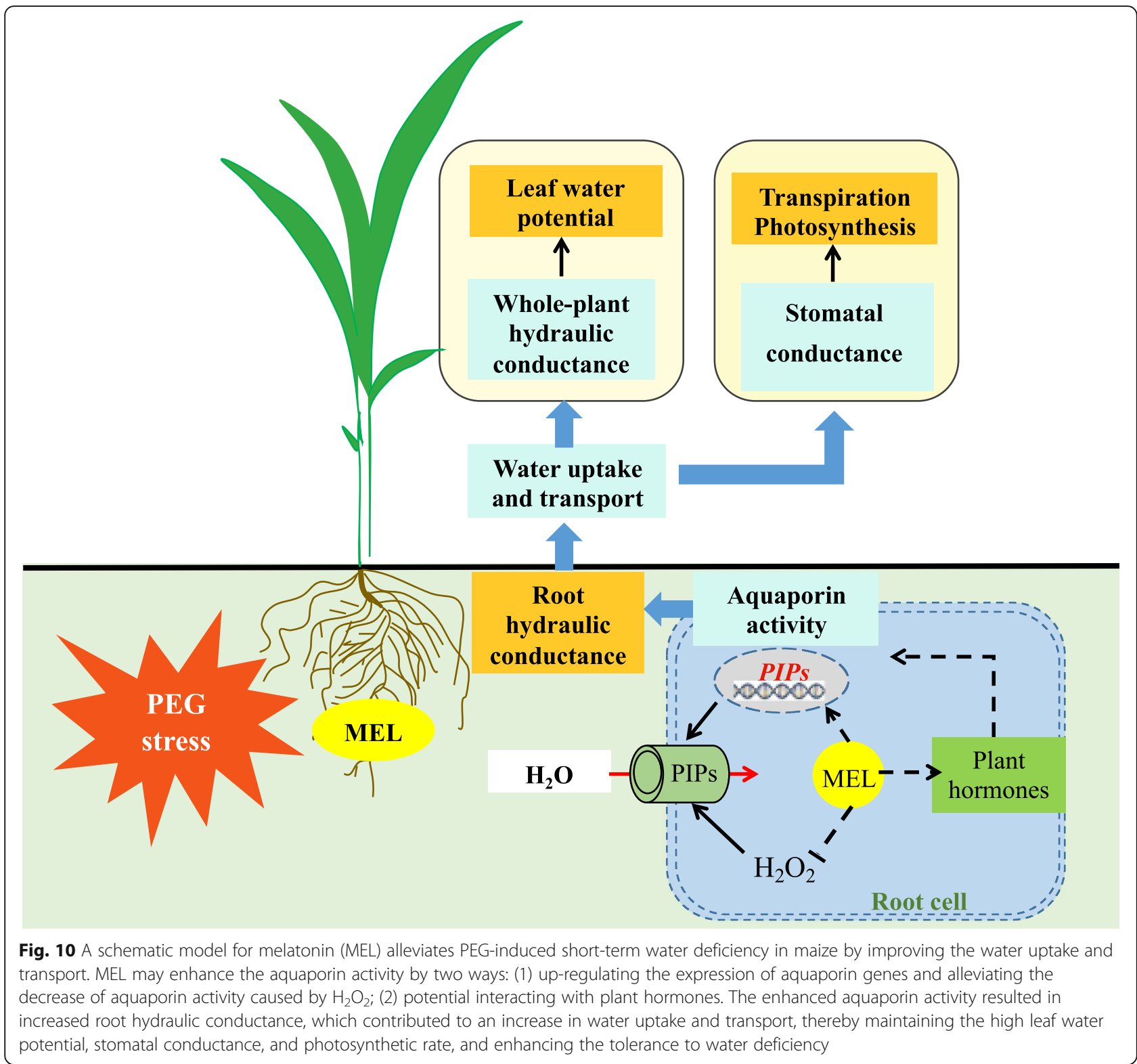

\section{Photosynthetic rate, stomatal conductance, and transpiration rate}

Three hours after PEG treatment, the photosynthetic rate, stomatal conductance, and transpiration rate were measured with a portable photosynthesis system (Li-6400; LICOR Inc., Lincoln, NE, USA). The top fully expanded leaf was placed in a $6 \mathrm{~cm}^{2}$ chamber at a photo flux density of $500 \mu \mathrm{mol} \mathrm{m}{ }^{-2} \mathrm{~s}^{-1}$ with leaf temperature was $28^{\circ} \mathrm{C}$.

\section{Whole-plant transpiration rate}

The transpiration rate was measured by gravimetric method according to Liu et al. [32] from the onset of PEG treatment. The seedlings were placed in a foilwrapped plastic bottle containing the original culture solution, and sealed with a sealing film to prevent water dispersion. The rate of water dispersion per unit time was determined using a balance. It was measured every 20 min during the first two hours and then measured every one hour until the end of PEG treatment. The leaves were scanned with a scanner and the leaf area of each plant was calculated using image analysis software (WinRHIZO PRO 2009, Canada). The whole plant transpiration rate was calculated by dividing the rate of water dispersion per unit time by the corresponding leaf area. Six replicates were included for each treatment.

\section{Leaf relative water content, leaf water potential and} osmotic potential

The upper fully expanded leaves were used for leaf relative water content (LRWC) measurement after three 
hours of PEG treatment according to Liu et al. [32]. The leaf was cut into $2 \mathrm{~cm}$ segments with scissors, and the fresh weight was quickly weighed with the balance. The leaf segments were placed in a $50 \mathrm{~mL}$ centrifuge tube and filled with distilled water for $6 \mathrm{~h}$, and then the total weight was measured after drying the water. Then, after drying at $70^{\circ} \mathrm{C}$ for more than $48 \mathrm{~h}$, the dry weight was weighed. The LRWC was calculated as: LRWC $=[($ Fresh weight -Dry wight)/ (Total weight -Dry weight)] $\times 100 \%$.

The leaf water potential was measured according to Chen et al. [39] by a pressure chamber (Model 3500, Soil Moisture Corp., Santa Barbara, CA, USA). Leaf was cut off in the middle and placed into the steel drum with the slit exposed about $1 \mathrm{~cm}$. After tightening the spiral collar, opened the main control valve and slowly pressurized at a rate of $0.05 \mathrm{MPa}$ per second. When the water film appeared in the slit, the pressure value was the water potential value of the leaf.

The leaf osmotic potential was measured as follows: The latest fully expanded leaves were shredded, mixed and inserted into a centrifuge tube which was previously punched at the bottom. After freezing in the liquid nitrogen, store at $-20{ }^{\circ} \mathrm{C}$. Frozen leaf samples were thawed at room temperature, then centrifuged at $4000 \mathrm{rpm}$ for 5 min to gather the cell sap and the cell sap was measured using a dew point microvolt meter (Model 5600, Wescor, Logan, UT, USA). Each treatment included six replicates.

\section{Osmotic potential of root xylem}

The osmotic potential of the root xylem sap was measured after three hours of PEG treatment according to the method of Liu et al. [32]. The shoot was cut off at the base of the root system and the xylem sap was collected using a pressure chamber (Model 3500, Soil Moisture Corp., Santa Barbara, CA, USA). The entire root system was sealed in the cylinder leaving $1 \mathrm{~cm}$ of mesocotyl exposed outside the rubber stopper. After tightening the spiral collar, opened the main control valve and applied a pressure less than the leaf water potential to cause the xylem sap to flow out of the incision. The xylem sap was collected in a $0.5 \mathrm{ml}$ centrifuge tube and its osmotic potential was measured using a dew point microvolt meter as mentioned above. Each treatment included six replicates.

\section{Whole-plant hydraulic conductance $\left(\mathrm{K}_{\text {plant }}\right)$}

The $K_{\text {plant }}$ was calculated according to the following equation [21]: $K_{\text {plant }}=$ Transpiration rate / (Soil water potential -Leaf water potential). The transpiration rate refers to the whole plant level determined gravimetrically. In hydroponic culture, the soil water potential (i.e. culture potential) was measured using a dew point microvolt meter as used above. In detail, the culture potential was $-0.03 \mathrm{MPa}$ under control condition or with MEL application. Under PEG treatment, the soil water potential (i.e. culture potential) was $-0.19 \mathrm{MPa}$. The leaf water potential was measured by a pressure chamber as introduced before. Each treatment included eight replicates.

\section{Root hydraulic conductance and root surface area}

The root hydraulic conductance $\left(\mathrm{Lp}_{\mathrm{r}}\right)$ was measured after three hours of PEG treatment with a pressure chamber (as mentioned above) according to the method of Miyamoto et al. [55]. Each shoot was cut off at the base of the root system leaving $1 \mathrm{~cm}$ of mesocotyl and the roots were enclosed in a steel chamber. The gas pressure $\left(\mathrm{P}_{\text {ages }}\right)$ in the chamber was raised in steps of $0.1 \mathrm{MPa}$ up to $0.5 \mathrm{MPa}$ and under each given pressure, the exuded sap was collected with absorbent cotton for $60 \mathrm{~s}$ and weighed. After that, the root surface area was determined using a scanner and analyzed by root image analysis software (WinRHIZO PRO 2009, Regent Inc., Canada). The water flow $\left(\mathrm{Jv}_{\mathrm{r}}\right)$ in $\mathrm{m}^{3} \mathrm{~m}^{-2} \mathrm{~s}^{-1}$, is the slopes of exuded sap weight and time referred to the unit root surface area. $\mathrm{Lp}_{\mathrm{r}}$ is calculated from the slopes of $\mathrm{Jv}_{\mathrm{r}}$ against driving force. L $\mathrm{p}_{\mathrm{r}}$ was determined according to the following equation: $\mathrm{Jv}_{\mathrm{r}}=\mathrm{Lp}_{\mathrm{r}} \times \mathrm{P}_{\text {gas }}$. Each treatment included six replicates.

\section{Transpiration rate in response to aquaporin inhibitor $\left(\mathrm{HgCl}_{2}\right)$ and anti-inhibitor (DTT)}

The changes in the transpiration rate in response to aquaporin inhibitor $\left(\mathrm{HgCl}_{2}\right)$ and anti-inhibitor (DTT) were used to investigating the aquaporin-mediated water transport according to the method of Liu et al. [32]. The seedlings were divided as follows: one group was used for determining the transpiration rate directly, another group was treated with $50 \mu \mathrm{M} \mathrm{HgCl}_{2}$ for $5 \mathrm{~min}$ and then rinsed with distilled water before determining the transpiration rate, and the third group was exposed to $50 \mu \mathrm{M} \mathrm{HgCl} 2$ for $5 \mathrm{~min}$ and then treated with $5 \mathrm{mM}$ DTT for $15 \mathrm{~min}$. After that, roots were washed with distilled water, then the whole-plant transpiration rate was determined gravimetrically. Each treatment included eight replicates.

\section{Expression levels of maize aquaporin genes}

Roots tips $(5 \mathrm{~cm})$ were sampled after three and six hours of PEG treatment, respectively. The expression levels of eight identified maize aquaporin genes were analyzed using quantitative real-time -PCR. Total RNA was extracted by a TakaRa MiniBEST Plant RNA Extraction Kit (TakaRa, Dalian, China) and cDNA synthesis was reverse transcribed by a PrimeScriptTM II 1st Strand cDNA Synthesis Kit (TakaRa, Dalian, China). Quantitative real-time PCR analysis was conducted by a 
LightCycler 480 II System (Roche, Basel, Switzerland) using a SYBR Premix Ex $\mathrm{Taq}^{\text {TM }}$ kit (TakaRa, Dalian, China). The relative expression levels of ZmPIPs were assessed using glyceraldehyde phosphate dehydrogenase $(G A P D H)$ as the internal standard. To confirm the specificity of primers to the target genes, normal PCR was run. Each treatment included three replicates and each replicate included three technical replicates. The genes and the sequences of their specific primers are presented in Table 1.

\section{$\mathrm{H}_{2} \mathrm{O}_{2}$ content measurement}

Three hours after PEG treatment, the roots of maize seedlings were sampled to measure the $\mathrm{H}_{2} \mathrm{O}_{2}$ content according to the method of Ryan et al. [56]. Root tissues $(0.3 \mathrm{~g})$ were ground into fine powder and homogenized with $2 \mathrm{~mL}$ cold $0.1 \%(\mathrm{w} / \mathrm{v})$ trichloroacetic acid. After centrifuged at $12,000 \mathrm{~g}$ for $30 \mathrm{~min}$ at $4{ }^{\circ} \mathrm{C}, 0.4 \mathrm{~mL}$ of the supernatant was mixed with $0.4 \mathrm{~mL} 10 \mathrm{mM}$ potassium phosphate buffer ( $\mathrm{pH} 7.0)$ and $0.8 \mathrm{~mL} 1 \mathrm{M} \mathrm{KI}$. The absorbance of the mixture was read at $390 \mathrm{~nm}$, and the content of $\mathrm{H}_{2} \mathrm{O}_{2}$ in the sample was calculated against a calibration curve using $\mathrm{H}_{2} \mathrm{O}_{2}$ standards. Each treatment included four replicates from four different individual plants.

\section{Statistical analysis}

All experiments were repeated at least twice. Data were statistically analyzed using Duncan test $(p<0.05)$ with SPSS 19.0 (IBM, USA). All plots were created using GraphPad Prism 7.00 and different letters indicated statistically significant differences at $p<0.05$.

Table 1 Primers of aquaporin genes and reference gene used in real time PCR experiments

\begin{tabular}{ll}
\hline Gene & Primer \\
\hline ZmPIP1;1 & cccctactatgttacgtggagttc \\
& gcggcatattacacaattggta \\
ZmPIP1;2 & ctcattttatgcgttgggatgt \\
& actgaaaccaagaaaaccctga \\
$Z m P I P 1 ; 5$ & cacgtggtcatcatcaggg \\
& cgtatgctgcatggttgct \\
$Z m P I P 2 ; 1$ & cgggtcgccttttttg \\
& cccttgagagtcacgacatga \\
$Z m P I P 2 ; 2$ & ggccttctaccaccagtacatc \\
& ggcctttcttagctctgctc \\
$Z m P I P 2 ; 5$ & tgtcgtcgttggttgcct \\
GAPDH & cacaacaatcacactagcttggaa \\
& agcaggtcgagcatcttcg \\
& ctgtagccccactcgttgtc \\
\hline
\end{tabular}

\section{Supplementary information}

Supplementary information accompanies this paper at https://doi.org/10. 1186/s12870-020-02432-1.

Additional file 1: Figure S1. Effects of melatonin (MEL) application and water deficiency stress (PEG) on the dry weight of maize seedlings in hydroponic culture. Figure S2. Effects of melatonin (MEL) application and drought stress on transpiration rate of maize seedlings in hydroponic culture.

\section{Abbreviations}

PEG: Polyethylene glycol; MEL: Melatonin; $K_{\text {plant: }}$ Whole-plant hydraulic conductance; $L p_{r}$ : Root hydraulic conductance; DTT: Dithiothreitol; LRWC: Leaf relative water content; $K_{\text {leaf: }}$ Leaf hydraulic conductance; $\mathrm{K}_{\text {stem: }}$ Stem hydraulic conductance; Pages: Gas pressure; Jvr: the water flow; GAPDH: Glyceraldehyde phosphate dehydrogenase; PIPs: plasma membrane intrinsic aquaporins (PIPs); TIPs: Tonoplast intrinsic aquaporins; NIPs: Nodulin 26-like aquaporins (NIPs); SIPs: Small basic intrinsic aquaporins

\section{Acknowledgements}

Not applicable.

\section{Authors' contributions}

SW and XD conceived and designed the study. YQ and JR carried out the experiments and analyzed the data. YL helped with the hydraulic measurement. YQ drafted the manuscript. LY and PL contributed to the editing of the manuscript. All authors read and approved the final manuscript.

\section{Funding}

This work was supported by National Key Technology Research \&Development Program of China (2018YFD1001000), the National Key Research and Development Program of China (2015BAD22B01), National Natural Science Foundation (51479189), and the 111 project of the Chinese Education Ministry (B12007).

Availability of data and materials

The data used in this study is available from the corresponding author on reasonable request.

Ethics approval and consent to participate

$\mathrm{N}$ applicable.

Consent for publication

All authors agreed to publish.

\section{Competing interests}

The authors declare that they have no competing interests.

\section{Author details}

${ }^{1}$ State Key Laboratory of Soil Erosion and Dryland Farming on the Loess Plateau, Institute of Soil and Water Conservation, Northwest A\&F University, Yangling 712100, Shaanxi, China. ${ }^{2}$ College of Life Sciences, Northwest A\&F University, Yangling 712100, Shaanxi, China. ${ }^{3}$ Institute of Soil and Water Conservation, Chinese Academy of Sciences \& Ministry of Water Resources, Yangling 712100, Shaanxi, China. ${ }^{4}$ College of Natural Resources and Environment, Northwest A\&F University, Yangling 712100, Shaanxi, China. ${ }^{5}$ College of Plant Protection, Shandong Agricultural University, Taian 271018, China.

Received: 21 February 2020 Accepted: 5 May 2020

Published online: 14 May 2020

\section{References}

1. Arnao MB, Hernández-Ruiz J. Melatonin: plant growth regulator and/or biostimulator during stress? Trends Plant Sci. 2014;19:789-97.

2. Arnao MB, Hernández-Ruiz J. Melatonin: a new plant hormone and/or a plant master regulator? Trends Plant Sci. 2019;24:38-48.

3. Hardeland R. Melatonin in plants and other phototrophs - advances and gaps concerning the diversity of functions. J Exp Bot. 2015;66:627-46. 
4. Weeda S, Zhang N, Zhao X, Ndip G, Guo Y, Buck GA, Fu C, Ren S. Arabidopsis transcriptome analysis reveals key roles of melatonin in plant defense systems. PLoS One. 2014;9:e93462.

5. Zhang N, Sun Q, Zhang H, Cao Y, Weeda S, Ren S, Guo YD. Roles of melatonin in abiotic stress resistance in plants. J Exp Bot. 2015;66:647-56.

6. Antoniou C, Chatzimichail G, Xenofontos R, Pavlou JJ, Panagiotou E, Christou A, Fotopoulos V. Melatonin systemically ameliorates drought stressinduced damage in Medicago sativa plants by modulating nitro-oxidative homeostasis and proline metabolism. J Pineal Res. 2017;62:e12401.

7. Fan J, Xie Y, Zhang Z, Chen L. Melatonin: a multifunctional factor in plants. Int J Mol Sci. 2018;19:1528.

8. Hasan MK, Ahammed GJ, Yin L, Shi K, Xia X, Zhou Y, Yu J, Zhou J. Melatonin mitigates cadmium phytotoxicity through modulation of phytochelatins biosynthesis, vacuol.ar sequestration, and antioxidant potential in Solanum lycopersicum L. Front Plant Sci. 2015;6:601.

9. Zhang HJ, Zhang N, Yang RC, Wang L, Sun QQ, Li DB, Cao YY, Weeda S, Zhao B, Ren S, Guo YD. Melatonin promotes seed germination under high salinity by regulating antioxidant systems, ABA and GA4 interaction in cucumber (Cucumis sativus L.). J Pineal Res. 2015;57:269-79.

10. Cui G, Zhao X, Liu S, Sun F, Zhang C, Xi Y. Beneficial effects of melatonin in overcoming drought stress in wheat seedlings. Plant Physiol Biochem. 2017; 118:138-49.

11. Li C, Tan DX, Liang D, Chang C, Jia D, Ma F. Melatonin mediates the regulation of ABA metabolism, free-radical scavenging, and stomatal behaviour in two Malus species under drought stress. J Exp Bot. 2015;66:669-80.

12. Wei W, Li QT, Chu YN, Reiter RJ, Yu XM, Zhu DH, Zhang WK, Biao M, Lin Q, Zhang JS, Chen SY. Melatonin enhances plant growth and abiotic stress tolerance in soybean plants. J Exp Bot. 2015;66:695-707.

13. Zuo B, Zheng X, He P, Wang L, Lei Q, Feng C, Zhou J, Li Q, Han Z, Kong J. Overexpression of MzASMT improves melatonin production and enhances drought tolerance in transgenic Arabidopsis thaliana plants. J Pineal Res. 2015;57:408-17.

14. Li C, Wang P, Wei Z, Liang D, Liu C, Yin L, Jia D, Fu M, Ma F. The mitigation effects of exogenous melatonin on salinity-induced stress in Malus hupehensis. J Pineal Res. 2012;53:298-306.

15. Manchester LC, Coto-Montes A, Boga JA, Andersen LP, Zhou Z, Galano A, Vriend J, Tan DX, Reiter RJ. Melatonin: an ancient molecule that makes oxygen metabolically tolerable. J Pineal Res. 2015:59:403-19.

16. Rodriguez C, Mayo JC, Sainz RM, Antolín I, Herrera F, Martín V, Reiter RJ. Regulation of antioxidant enzymes: a significant role for melatonin. J Pineal Res. 2010;36:1-9.

17. Allegra M, Reiter RJ, Tan DX, Gentile C, Tesoriere L, Livrea MA. The chemistry of melatonin's interaction with reactive species. J Pineal Res. 2003;34:1-10.

18. Shi H, Jiang C, Ye T, Tan D, Reiter RJ, Zhang H, Liu R, Chan Z. Comparative physiological, metabolomic, and transcriptomic analyses reveal mechanisms of improved abiotic stress resistance in bermudagrass [Cynodon dactylon (L). Pers.] by exogenous melatonin. J Exp Bot. 2015;66:681-94.

19. Wang P, Sun X, Li C, Wei ZW, Liang D, Ma FW. Long-term exogenous application of melatonin delays drought-induced leaf senescence in apple. J Pineal Res. 2013;54:292-302.

20. Gleason SM. Evolutionary outcomes should inform strategies to increase drought tolerance. Nat Plants. 2015;1:15114.

21. Martre P, Morillon R, Barrieu F, North GB, Nobel PS, Chrispeels MJ. Plasma membrane aquaporins play a significant role during recovery from water deficit. Plant Physiol. 2002;130:2101-10.

22. Vandeleur RK, Mayo G, Shelden MC, Gilliham M, Kaiser BN, Tyerman SD. The role of plasma membrane intrinsic protein aquaporins in water transport through roots: diurnal and drought stress responses reveal different strategies between isohydric and anisohydric cultivars of grapevine. Plant Physiol. 2009;149:445-60.

23. Javot $\mathrm{H}$, Maurel $\mathrm{C}$. The role of aquaporins in root water uptake. Ann Bot. 2002;90:301-13.

24. Szczepkowska A, Skowroński MT, Kowalewska M, Milewski S, Skipor J. Effect of melatonin from slow-release implants on aquaporins (AQP1 and AQP4) in the ovine choroid plexus. Czech J Anim Sci. 2017;63:32-42.

25. Sun $Q$, Zhang $N$, Wang J, Zhang H, Li D, Shi J. Melatonin promotes ripening and improves quality of tomato fruit during postharvest life. J Exp Bot. 2015; 66:657-68.

26. Cornic G, Prioul JL, Louason G. Stomatal and non-stomatal contribution in the decline in leaf net $\mathrm{CO} 2$ uptake during rapid water stress. Physiol Plant. 2010;58:295-301.
27. Gleason SM, Wiggans DR, Bliss CA, Comas LH, Cooper M, Dejonge KC, Young JS, Zhang H. Coordinated decline in photosynthesis and hydraulic conductance during drought stress in Zea mays. Flora. 2016;227:1-9.

28. Chaves MM, Flexas J, Pinheiro C. Photosynthesis under drought and salt stress: regulation mechanisms from whole plant to cell. Ann Bot. 2008;103: $551-60$.

29. Martínez-Vilalta J, Garcia-Forner N. Water potential regulation, stomatal behaviour and hydraulic transport under drought: deconstructing the iso/ anisohydric concept. Plant Cell Environ. 2017;40:962-76.

30. Flower DJ, Ludlow MM. Contribution of osmotic adjustment to the dehydration tolerance of water-stressed pigeon pea (Cajanus cajan (L.) millsp.) leaves. Plant Cell Environ. 1986;9:33-40.

31. Ding $F$, Wang $G$, Wang $M$, Zhang $S$. Exogenous melatonin improves tolerance to water deficit by promoting cuticle formation in tomato plants. Molecules. 2018:23:e1605.

32. Liu P, Yin L, Deng X, Wang S, Tanaka K, Zhang S. Aquaporin-mediated increase in root hydraulic conductance is involved in silicon-induced improved root water uptake under osmotic stress in Sorghum bicolor L. J Exp Bot. 2014;65:4747-56.

33. Brodribb TJ, Holbrook NM. Stomatal closure during leaf dehydration, correlation with other leaf physiological traits. Plant Physiol. 2003;132: 2166-73.

34. Sutka M, Li G, Boudet J, Boursiac Y, Doumas P, Maurel C. Natural variation of root hydraulics in Arabidopsis grown in normal and salt-stressed conditions. Plant Physiol. 2011;155:1264-76.

35. Steudle E. Water uptake by plant roots: an integration of views. Plant Soil. 2000;226:45-56.

36. Boursiac Y, Chen S, Luu DT, Sorieul M, van den Dries N, Maurel C. Early effects of salinity on water transport in Arabidopsis roots. Molecular and cellular features of aquaporin expression. Plant Physiol. 2005;139:790-805.

37. Horie T, Kaneko T, Sugimoto G, Sasano S, Panda SK, Shibasaka M, Katsuhara M. Mechanisms of water transport mediated by PIP aquaporins and their regulation via phosphorylation events under salinity stress in barley roots. Plant Cell Environ. 2011;52:663-75.

38. Hachez C, Veselov D, Ye Q, Reinhardt H, Knipfer T, Fricke W, Chaumont F. Short-term control of maize cell and root water permeability through plasma membrane aquaporin isoforms. Plant Cell Environ. 2011;35:185-98.

39. Chen D, Cao B, Wang S, Liu P, Deng X, Yin L, Zhang S. Silicon moderated the $k$ deficiency by improving the plant-water status in sorghum. Sci Rep. 2016;6:22882.

40. Tyerman SD, Niemietz CM, Bramley HH. Plant aquaporins: multifunctional water and solute channels with expanding roles. Plant Cell Environ. 2002;25: $173-94$

41. Hachez C, Besserer A, Chevalier AS, Chaumont F. Insights into plant plasma membrane aquaporin trafficking. Trends Plant Sci. 2013;18:344-52.

42. Sade N, Shatil-Cohen A, Attia Z, Maurel C, Boursiac Y, Kelly G, Granot D, Yaaran A, Lerner S, Moshelion M. The role of plasma membrane aquaporins in regulating the bundle sheath-mesophyll continuum and leaf hydraulics. Plant Physiol. 2014;166:1609-20.

43. Alexandersson E, Danielson JA, Råde J, Moparthi VK, Fontes M, Kjellbom P, Johanson U. Transcriptional regulation of aquaporins in accessions of Arabidopsis in response to drought stress. Plant J. 2010;61:650-60.

44. Boursiac Y, Boudet J, Postaire O, Luu DT, Tournaire-Roux C, Maurel C. Stimulus-induced downregulation of root water transport involves reactive oxygen species-activated cell signalling and plasma membrane intrinsic protein internalization. Plant J. 2008:56:207-18.

45. Ding L, Gao C, Li Y, Li Y, Zhu Y, Xu G, Shen Q, Kaldenhoff R, Kai L, Guo S. The enhanced drought tolerance of rice plants under ammonium is related to aquaporin (AQP). Plant Sci. 2015;234:14-21.

46. Parent B, Hachez C, Redondo E, Simonneau T, Chaumont F, Tardieu F. Drought and abscisic acid effects on aquaporin content translate into changes in hydraulic conductivity and leaf growth rate: a trans-scale approach. Plant Physiol. 2009;149:2000-12.

47. Ruiz-Lozano JM, Alguacil MM, Bárzana G, Vernieri P, Aroca R. Exogenous $A B A$ accentuates the differences in root hydraulic properties between mycorrhizal and non mycorrhizal maize plants through regulation of PIP aquaporins. Plant Mol Biol. 2009;70:565-79.

48. Boursiac Y, Prak S, Boudet J, Postaire O, Luu DT, Tournaire-Roux C, Santoni V, Maurel $C$. The response of Arabidopsis root water transport to a challenging environment implicates reactive oxygen species- and phosphorylationdependent internalization of aquaporins. Plant Signal Behav. 2008;3:1096-8. 
49. Henzler T, Ye Q, Steudle E. Oxidative gating of water channels (aquaporins) in Chara by hydroxyl radicals. Plant Cell Environ. 2004;27:1184-95.

50. Erland LAE, Saxena PK, Murch SJ. Melatonin in plant signaling and behavior. Funct Plant Biol. 2018:45:58-69.

51. Ciani E, Fontaine R, Maugars G, Mizrahi N, Mayer I, Levavi-Sivan B, Weltzien F. Melatonin receptors in Atlantic salmon stimulate cAMP levels in heterologous cell lines and show season-dependent daily variations in pituitary expression levels. J Pineal Res. 2019;67:e12590.

52. Dema A, Faust D, Lazarow K, Wippich M, Neuenschwander M, Zühlke K, Geelhaar A, Pallien T, Hallscheidt E, Eichhorst J, Wiesner B, Černecká H, Popp O, Mertins P, Dittmar G, Kries JPV, Klussmann E. Cyclin-dependent kinase 18 controls trafficking of aquaporin-2 and its abundance through ubiquitin ligase STUB1, which functions as an AKAP. Cells. 2020;9:673.

53. Tan DX, Hardeland R, Manchester LC, Korkmaz A, Ma S, Rosales-Corral S, Reiter RJ. Functional roles of melatonin in plants, and perspectives in nutritional and agricultural science. J Exp Bot. 2012;63:577-97.

54. Zhang N, Sun Q, Li H, Li X, Cao Y, Zhang H, Li S, Lei Z, Qi Y, Ren S, Zhao B, Guo YD. Melatonin improved anthocyanin accumulation by regulating gene expressions and resulted in high reactive oxygen species scavenging capacity in cabbage. Front Plant Sci. 2016;7:197.

55. Miyamoto N, Steudle E, Hirasawa T, Lafitte R. Hydraulic conductivity of rice roots. J Exp Bot. 2001:52:1835-46.

56. Ryan A, Cojocariu C, Possell M, Davies WJ, Hewitt CN. Defining hybrid poplar (Populus deltoides x Populus trichocarpa) tolerance to ozone: identifying key parameters. Plant Cell Environ. 2009;32:31-45.

\section{Publisher's Note}

Springer Nature remains neutral with regard to jurisdictional claims in published maps and institutional affiliations.

Ready to submit your research? Choose BMC and benefit from:

- fast, convenient online submission

- thorough peer review by experienced researchers in your field

- rapid publication on acceptance

- support for research data, including large and complex data types

- gold Open Access which fosters wider collaboration and increased citations

- maximum visibility for your research: over $100 \mathrm{M}$ website views per year

At $\mathrm{BMC}$, research is always in progress.

Learn more biomedcentral.com/submissions 